\title{
La opción por los pobres hoy
}

\section{Gustavo Gutiérrez, Lima}

Siempre ha sido para mí una gracia poder estar presente en estos aniversarios de la entrega martirial de monseñor Romero. Son jalones muy importantes en nuestras vidas, entre otras cosas, o tal vez sobre todo, porque nos ponen en contacto y sin cortapisas con las fuentes mismas del mensaje cristiano. A los que estamos aquí, y a muchos otros, nos llaman a una reflexión. Yo diría, incluso, a una revisión de nuestras vidas.

Recordar a Romero significa volvernos a poner ante el reto del Evangelio, su mensaje y su vida, preguntarnos por nuestra fidelidad, y también, ¿por qué no?, por nuestras infidelidades. Monseñor nos desafía a mantener muy ligadas la cercanía a Dios y la cercanía al pobre.

Jon Sobrino ha dicho hace un momento que él fue quien escogió el título de esta ponencia mía. Siendo él jesuita y yo dominico, muestra la intuición de Jon. Estoy muy de acuerdo con el título y su importancia. Y otra cosa más antes de entrar en materia. En la introducción, José María Tojeira ha mencionado lo que algunos están diciendo sobre "la muerte de la teología de la liberación". Y también veo que ustedes están interesados en el tema porque sobre eso mismo le han preguntado a Xavier Alegre después de su excelente ponencia. Yo sólo les puedo asegurar -en este momento no sé muy bien si como testimonio o antitestimonio- que a mí nunca me han invitado al entierro de la teología de la liberación. Y creo que algún mérito he hecho para que me inviten.

El papa Juan XXIII, el 11 de septiembre de 1962, exactamente un mes antes del inicio del Vaticano II, en un radiomensaje relacionado con el Concilio, de manera algo sorprendente pronunció unas palabras que nos han marcado mucho: "la Iglesia de los pobres". Voy a repetir toda la frase, que es muy breve: "Frente a los países subdesarrollados, es decir, frente a la pobreza en el mundo, la Iglesia es y quiere ser una realidad germinal y un proyecto, la Iglesia de todos y, particularmente, la Iglesia de los pobres". No hay una palabra de más. Este planteamiento 
fue muy importante, aunque, a decir verdad, y por razones que fácilmente podemos comprender, no tuvo gran peso en los documentos del Concilio. Pero sí tuvieron gran repercusión entre nosotros, en este continente de mayoría cristiana $-\mathrm{y}$ de alta proporción católica- y al mismo tiempo de población pobre y marginada. Un escándalo, ¿no es cierto?

Si por cristiano entendemos todo lo que Xavier nos ha recordado hace un momento, vivir en un continente cristiano con esta pobreza inhumana, esta muerte de tantas personas, prematura e injusta, es una contradicción terrible y escandalosa. Por esa razón la perspectiva de la "Iglesia de los pobres" nos marcó tanto, y en los años que siguieron al Concilio fue agarrando fuerza en América Latina. A ello ayudaron también las circunstancias históricas y sociales del continente, pues creció la presencia de los pobres -incluso en forma novedosaen la escena histórica, social y política de América Latina. Esas experiencias y esas reflexiones se sintieron con mucha fuerza en Medellín, en 1968.

\section{Memoria, recuerdo y servicio}

Para hablar de lo que es y debe ser la realidad y del proyecto de una "Iglesia de los pobres" quisiera tomar como hilo conductor un breve texto de monseñor Romero: "Hay un criterio para saber si Dios está cerca de nosotros o si está lejos, todo aquel que se preocupe del hambriento, del desnudo, del pobre, del desaparecido...".

Comienza con una clara referencia a Mateo 25, pero continúa mencionando lo que no está explícitamente en Mateo: "el torturado, el prisionero, toda carne que sufre". Llama al ser humano "carne", y dice que la carne que sufre "tiene cerca a Dios". El que se preocupa del pobre, del desaparecido, tiene cerca a Dios. Ese es el criterio. "La garantía de mi plegaria es muy fácil de conocer, cómo me porto con el pobre, pues ahí está Dios".

Como dije, quisiera comentar esta frase y tomarla como hilo conductor, porque me parece que, entre muchas otras frases y otros acentos que hubiéramos podido tomar de monseñor Romero, ésta indica bien lo que mencionaba hace unos minutos: la cercanía al pobre y la cercanía a Dios.

Comienzo con este lenguaje de doble cercanía, aunque, a un nivel más profundo, lo más importante que hizo monseñor fue hacer ver el lazo que une a esas dos cercanías, hasta el punto de decir que si faltaba una de ellas, tampoco existía la otra. No hay manera de acercase a Dios sin acercarse al pobre. Y desde una perspectiva cristiana, acercarse al pobre es acercarse a Dios. Y mantengo el término "acercarse" porque está en el texto que he leído, pero también porque es hermoso. No se trata únicamente de "creer", sino de "estar cerca", familiarmente cerca. 
Mi primer punto tiene coincidencias con el primer punto de Xavier. Lo expondré de dos maneras, aunque el tema de fondo es muy similar, si no el mismo.

Una primera exigencia de una comunidad cristiana y eclesial $-\mathrm{y}$ voy a usar términos colectivos, aunque no para escapar del desafío personal- es hacer suya la práctica de Jesús. De eso se trata, de hacer nuestra la práctica de Jesús. Ahora bien, según los Evangelios, Jesús nos dejó dos indicaciones sobre cómo hacerlo, y para ello se refirió a un tema bíblico central: la memoria de Dios. La Biblia está llena de esa idea. "Acuérdate que Yahvé te sacó de Egipto". Los salmos, dirigidos a Dios como oración, frecuentemente entonan un "acuérdate". La raíz hebrea de "memoria" aparece cientos de veces en el Antiguo Testamento, y también en el Nuevo.

Antes de entrar en detalles, digamos una palabra sobre lo central de la "memoria". La "memoria" saca a la luz el recuerdo, y en cierto modo lo libera de sus límites espaciales y temporales para hacerlo vivir en el presente. Esto no tiene nada de raro, y, así, cuando le decimos a una persona que se va de viaje "acuérdate de mí", no le estamos diciendo "acuérdate de que éramos amigos, amigas", sino "acuérdate de que lo seguimos siendo". La memoria apunta a un presente, no queda fijada en un pasado y menos en un pasado doloroso.

Otra cosa es la nostalgia. Esta supone alguna forma dolorosa de conocimiento que nos puede remitir a realidades de vida anteriores. A veces, nos ponemos muy nostálgicos y pensamos que hubo momentos en nuestra vida, en la vida política de América Latina, en la Iglesia, que eran sensacionales. Nos pasamos el tiempo lamentándolo, pero no lo podemos volver a vivir. Por mucho que manoseemos el calendario, la historia no regresa. Por eso a los muy nostálgicos les suelo aconsejar que escuchen durante media hora música de boleros. Así se desahogan y vuelven al presente.

Pues bien, la memoria va a lo esencial, va al significado de las cosas, no a los detalles. Los cuatro Evangelios son memoria, memorias de Jesús, y por eso van al fondo. Coinciden en lo esencial y se diferencian en los detalles, lo cual ocurre siempre. Permítanme una pequeña comparación. Ocurre un accidente en la esquina y varias personas lo presencian. Una dice: "el auto venía por la derecha"; otra dice: "no, venía por la izquierda"; "era de color verde"; "no, era azul". Lo que importa es que es un carro, ¿no? Eso son los Evangelios. Son memorias porque van a lo esencial, al fundamento. Entonces, cuando digo que nos han dejado memorias me estoy refiriendo a este tipo de memoria.

Y algo más sobre la noción de "memoria". En la Biblia la memoria debe ser puesta en práctica. No es un recuerdo simplemente conceptual, agradable o desagradable. Es sobre todo algo que nos lleva a vivir. La memoria que nos es más conocida $-\mathrm{y}$ voy a abreviar mucho- es la de la última cena: "hagan esto 
en memoria mía". La "memoria" está muy clara. ¿Y qué es "esto”? ¿Es solamente la cena, el rito de la cena? No. Se trata de hacer memoria de Jesús, de su vida, su enseñanza, sus curaciones, sus diálogos, su compasión, su muerte, sus sufrimientos, su Resurrección. De eso se trata el "hagan esto en memoria mía". Es la memoria de Jesús, ahora en el contexto de la cena.

Y hay que saber cómo hacerlo, porque de alguna manera la institución de la eucaristía sintetiza muchos aspectos y es una celebración comunitaria. Memoria de Jesús no es solo una memoria ritual, pero tampoco va contra el rito; lo que hace es darle sentido. El rito o la costumbre puede ser muy formal, pero si no tiene contenido, no tiene sentido. A esto fueron muy sensibles los profetas del Antiguo Testamento, y Jesús los cita: "No quiero sacrificios, quiero corazones contritos". No es tanto no querer el sacrificio, sino decir que el sacrificio, el acto cultual, puede estar enteramente vacío. El corazón contrito, arrepentido, debe darle contenido. Jesús nos dirá en el Evangelio de Juan que mandará al paráclito, al abogado, al defensor, para que nos recuerde todo lo que él había enseñado. Y también en Timoteo hay textos que repiten "acuérdense de Jesucristo". En la memoria de Jesús se trata, pues, de recordar la cena con todo el contenido del testimonio que Jesús dio cuando estuvo presente en nuestra historia.

Paso ahora a una segunda forma de "memoria" sin que aparezca la palabra. En el Evangelio de Juan aparece la última cena de despedida con largos discursos, pero sin institución de la eucaristía. Juan no habla de ella. ¿Qué hace en su lugar? Jesús toma una toalla, una jofaina con agua y lava los pies a sus amigos, servicio humilde con el que en la época se acostumbraba a recibir a los invitados. Lo hacían los sirvientes y, a veces, el dueño de casa. Jesús es el anfitrión, les lava los pies y -después de las palabras de Pedro, siempre primario- les dice: "¿ustedes han comprendido lo que he hecho? Lo he hecho para que ustedes también lo hagan". Es decir, "les he dado ejemplo para que ustedes también lo hagan". Noten la presencia de los dos verbos, "hagan esto en memoria mía", "para que ustedes también lo hagan". Se trata, pues, de "hacer" el servicio sencillo y humilde, en la forma como el maestro, el Señor, lava los pies a sus amigos, sus discípulos. Una vez más, la memoria va a lo esencial. No se trata de hacerlo litúrgicamente el Jueves Santo, en que se pierde mucho de su significación. Lo que queda, el sentido, es el servicio a otra persona.

Estas dos memorias son las que nos deja Jesús para que hagamos nuestra su práctica. Es la práctica de recordarlo plenamente, de recordar su enseñanza, su testimonio, su presencia en medio de nosotros, y la práctica del servicio. Pero hay que tener presente las dos memorias - "hagan, hagan"-, son inseparables, ambas deben estar presentes. "A mí me gusta mucho la eucaristía, pero no tengo mucho tiempo, tengo trabajo". Y se puede perder uno de los dos lados. Pero eso es perder los dos. El que dice que se quiere quedar con la mitad, se queda sin nada. Y la eucaristía pierde sentido, si no está allí el servicio. 
Y además recuerdan el texto de Mateo en el capítulo 5: "si en el momento de ir a presentar tu ofrenda ante el altar recuerdas que tu hermano tiene algo contra ti, da media vuelta, reconcíliate con tu hermano y vuelve a presentar la ofrenda". Si me permiten la comparación geométrica, es como una elipse, no un círculo. Hay dos centros. Ir a presentar al altar es contemplación, es dimensión religiosa, eso va hacia Dios. Pero si recuerdas que tu hermano tiene algo contra ti, no la presentes, reconcíliate con tu hermano y, una vez reconciliado, ve a presentar la ofrenda. De nuevo, la memoria apunta al significado. La reconciliación, es decir, la comunión, la amistad con el hermano, la hermana, es condición para ofrecer algo ante el altar.

Al hablar de estas cosas, bien podemos recordar una frase de San Vicente de Paúl. Ese gran santo dice en una carta enviada a las religiosas vicentinas, las hermanas de la caridad: "Si fuera voluntad de Dios que tuvieran que asistir a un enfermo en domingo, en vez de oír misa, aunque esto fuera obligación, habría que hacerlo". Y termina con esta frase brillante: "A eso se llama dejar a Dios por Dios". Se deja a Dios porque no se va a misa, pero en verdad no se deja a Dios. No está diciendo que la misa no tiene importancia, sino que está recordando esta otra memoria: "he hecho esto para que ustedes también lo hagan". Ya dije que no se puede escoger una de las dos memorias. Lo correcto sería hablar de una sola memoria que comprende estos dos aspectos. Esto es lo que va construyendo una comunidad cristiana.

Una Iglesia de los pobres, como la que construyó monseñor Romero, Iglesia de todos, pero particularmente de los pobres, tendrá que vivir esas dos memorias. Una cosa muy impresionante de monseñor Romero es justamente la unidad con que vivió ambas cosas, la dimensión religiosa y la humildad de su disposición al servicio y sencillez. Eso es lo que hizo en su vida. Fue alguien profundamente inmerso en la historia de su país y del mundo, y, al mismo tiempo, sumamente atento a dar gracias al Señor.

En el comienzo del Evangelio de Lucas hay una oración, un salmo, que conocemos bien. Es el Magnificat, en donde están estos dos aspectos. Comienza: "Engrandece mi alma el Señor", y toda la primera parte es acción de gracias por los bienes, por las gracias que esta joven judía ha recibido de Dios. Luego, en la segunda parte, habla de derribar a los poderosos de sus tronos y de despedir a los ricos con las manos vacías.

Un conocido político francés de comienzos del siglo XX escribió que habría que pedir a Roma que cambiara ese texto del Evangelio. Ignorancia. El Magnificat es un texto que anticipa el capítulo cuarto del Evangelio. Mantiene claramente las dos cosas. El anuncio de la buena nueva a los pobres y la acción de gracias. Ésta deber estar acompañada y sostenida por el servicio, y el servicio iría, de algún modo, colocado en el contexto de la acción de gracias. Creo que esto debe ser una nota de la Iglesia de los pobres. No es una Iglesia aparte de la Iglesia. Es una Iglesia que vive las dos memorias. 


\section{Gratuidad y justicia}

Quisiera pasar a un segundo punto. Esas memorias, o esa "sola memoria", en unidad, pero sin confusión, deben ser comunicadas. Es lo que Isaías pide en el capítulo 50: "hay que tener lengua de discípulo". Y aquí hay también como dos carriles. El primero es el lenguaje de la gratuidad, ya mencionada. El Dios que nos ama aunque seamos pecadores incluso antes de que existiéramos, como dice Efesios en el primer capítulo: "nos llamó a ser hijos e hijas de Dios antes de la creación del mundo". El lenguaje de la gratuidad, no es solo el lenguaje de la acción de gracias, sino también de proceder gratuitamente. En la primera carta de Juan, en frase breve y maciza, "Dios nos amó primero". Es el punto de partida. Nuestro amor por Él y por los demás es una respuesta a la iniciativa de amor que tiene Dios: "nos amó primero". Y otra sentencia, también joánica dice: "ámense como yo los he amado", es decir, gratuitamente. "Tanto amó Dios al mundo que envió a su propio hijo", y hay que amar como él.

Eso pone una condición a la evangelización, que Bartolomé de las Casas cumplió a cabalidad en la primera evangelización en este continente. Es lo que dice Jesús en Mateo. Debemos "dar gratis lo que hemos recibido gratis". Parece sencillo, ¿verdad? Pero si ese amor de Dios es gratuito, démoslo también gratuitamente. Lo que Bartolomé de las Casas tenía en mente al decir la frase mencionada era una teología, increíble pero real, en que se suponía, o se pensaba, que Dios había dado las minas y las riquezas de este continente a los europeos para que, a cambio, estos quisieran llegar a evangelizar.

Incluso hay una parábola de la segunda mitad del siglo XVI que dice: "Había un rey que tenía dos hijas, una muy bonita y la otra muy fea. En un momento dado decidió casarlas, y, claro, cuando presentó a la bonita, había cola de pretendientes, naturalmente. A la presentación de la fea no llegó nadie. Entonces, le dio una dote, una gran riqueza, y así las dos hijas se pudieron casar". ¿Qué significa esta parábola? Europa era tan bonita que los evangelizadores corrieron presurosos a evangelizarla. Pero América, estos indios, no es lo mismo. Para que alguien venga a evangelizar acá hay que darle una mina, un terreno. Si no, no vendrían. Todo eso está escrito en un documento de la historia peruana, que es además muy crítico en contra de De las Casas.

Volvamos al tema: "dar gratis lo que hemos recibido gratis". No se trata solo del amor gratuito de Dios, sino que también el nuestro debe ser gratuito. Hay muchas personas que hablan de "los pobres agradecidos", y a esos es a los que hay que ayudar. Pero hay que ayudar a alguien no porque agradezca, sino porque es pobre. Y la razón es "dar gratis lo que hemos recibido gratis".

Y hay algo más en el lenguaje de la gratuidad $-\mathrm{y}$ cuando hablo de lenguaje no me refiero únicamente a palabras, sino también a gestos, actitudes-. Es el lenguaje de la amistad. La amistad es el terreno del amor y de la gratuidad. 
Recuerden el texto de Juan: "no los llamo ya siervos porque el siervo no sabe lo que hace su amo, los he llamado amigos". Y añade la razón, que es lo importante: "porque todo lo que dice mi Padre se lo he dado a conocer". La razón de llamarlos "amigos" es que el Hijo ha compartido lo que el Padre le ha dado, y al compartirlo los hace amigos y no siervos. El texto dice que al siervo le dan una orden y la cumple, el amigo no. Al amigo no se le puede dar una orden ni hay que explicarle por qué quiere uno algo.

Somos amigos, no siervos, y la amistad es una cuestión de igualdad. No hay amor auténtico si no hay igualdad entre las personas - me refiero a la igualdad fundamental, pues puede haber diferencias de todo tipo, de edad, de conocimientos-. Pero hay una dignidad humana que nos iguala. Habría que decir que no hay amor sino entre iguales; si no es así, lo que hay es protección, engreimiento, favor que hacemos. El amor supone igualdad.

En la Conferencia Episcopal de Aparecida hay un hermoso texto sobre la amistad. "Solo la cercanía que nos hace amigos nos permite apreciar profundamente los valores de los pobres de hoy, sus legítimos anhelos, y su modo propio de vivir la opción por los pobres debe conducirnos a la amistad con los pobres". No demos esto por supuesto. Se puede hacer una opción por una clase social, un género, una cultura, una etnia. Y es legítimo. Pero lo que quiero señalar es que el compromiso debe ser fundamentalmente con las personas. Ellas, y esto hay que tenerlo en cuenta, pertenecen a esas categorías, pero el compromiso es con las personas, con María, Pedro, Juan, Luzmila, es con ellos y ellas.

Muchos de ustedes tienen experiencia de trabajar en ambiente pobre y saben lo que eso significa y lo que significa para los pobres. Es también lo que se planteaba muy claramente monseñor Romero en unos de sus textos, hablando de lo que habían hecho con unos catequistas, Felipe de Jesús y otros. A uno lo llamaban Polín. Dice monseñor: "los he llorado de veras y con ellos a otros muchos que fueron catequistas, trabajadores de nuestras comunidades". Los lloró, eso es amistad. Uno llora ante la persona que uno quiere. Lloró. Si quieren, esto es compasión en el mejor sentido del término. Pero es gratuidad, forma parte de este mundo de la gratuidad. Y quiero aclarar que no he empleado el término "gratuidad" como sinónimo de "arbitrario", como a veces ocurre en el lenguaje corriente: "gratuitamente, me insultó". Con "gratuidad" me he referido a este gesto primero: Dios "nos amó primero"; y, naturalmente, nosotros también debemos hacerlo.

Nuestro compromiso y solidaridad con el pobre significará tomar la iniciativa, yendo hacia ellos, como en la famosa parábola del samaritano, saliendo de nuestro camino y acercándonos a un hombre desnudo, personaje central de la parábola. Por cierto, el herido en el camino es el único personaje del cual no se dice que tuviera alguna responsabilidad. De todos los otros sí: de los ladrones, su responsabilidad era robar; el levita tenía el estudio; el sacerdote, el culto. El 
samaritano no sabemos qué hacía, pero era samaritano, miembro de un pueblo marginado y despreciado por el mundo judío. Finalmente, el hospedero. De todos sabemos algo, del herido nada. ¿Quién era? "Un cierto hombre", "anthropos", que puede significar "anónimo". Narrativamente hablando, el personaje central es este marginado al borde del camino casi muerto. De eso se trata. Desde otro punto de vista, también el samaritano es central. Es el que tiene el gesto. No se preguntó: "¿merecerá este hombre que lo ayude, será compatriota mío, será hebreo, qué hará?". No se preguntó nada de eso. Simplemente, salió y lo atendió.

El segundo lenguaje es el profético o el de la justicia. De alguna manera corresponde a la memoria del servicio, así como el de la gratuidad corresponde a la memoria de la acción de gracias por la presencia de Jesús entre nosotros. Con el lenguaje de la justicia, estamos otra vez ante un tema absolutamente central en la Biblia. El tema es tan rico que para Pablo la "justificación", justificar, hacer justicia, llegó a convertirse en salvación. Estamos hablando de justicia, en lenguaje contemporáneo del reconocimiento de los derechos de otra persona. Pero semánticamente el término se carga de tanto significado que se convierte en sinónimo de salvación.

En la Biblia es muy claro que ese lenguaje remite a la justicia social y está ligada fundamentalmente al pobre. No es que no haya justicia para otras personas, pero el acento está puesto en la justicia hecha al pobre, al más débil de la sociedad. Este lenguaje profético tiene en cuenta el detalle de la historia, lo que sucede día a día con las injusticias, postergaciones, maltratos, muertes, sufrimientos. Así como el hablar de Dios es lenguaje de gratuidad, contemplativo o místico - no místico en el sentido de misterio del que no entendemos nada, sino como algo que no entra totalmente en nuestros conceptos-, y es lenguaje de creación de un mundo justo. Monseñor Romero se quejaba de un lenguaje "muy espiritualista" - noten que recalca el "muy" y el "espiritualista", pues hay que tener un respeto muy grande por la palabra "espiritual"-. Denunciaba "una palabra muy espiritualista, sin compromiso con la historia, que puede sonar en cualquier parte del mundo porque no es de ninguna parte y no crea problemas ni conflictos".

La comunicación de las memorias tiene estas dos vertientes, pero como en el caso anterior, tampoco podemos separar el lenguaje de la gratuidad, o contemplativo, del lenguaje profético, o de la justicia. "Si queremos quedarnos con uno, perdemos los dos", ciertamente en una perspectiva bíblica y cristiana. Hay una frase muy linda de san Agustín. De una homilía. Y san Agustín es el único predicador que tenía sermones más largos que los de monseñor Romero. Con una diferencia. Hipona era un pueblo muy chico, no había circo, el único entretenimiento era la homilía del obispo. Pues bien, san Agustín, que es tan fino para sus cosas, le decía a su gente: "canten, pero caminen". "Canten", oración, canto, agradecimiento a Dios. Pero "caminen", historia. Es una intuición cris- 
tiana. No se queden cantando todo el día, con eso no somos discípulos de Jesús. Y no se trata únicamente de caminar, sino de dar gracias. Hay caminantes que cantan en el camino, van caminando y cantando. Eso es lo que debemos hacer. El canto como algo gratuito, bello, no estrictamente necesario. Y el caminar, porque hay que ir hacia un lugar. Es contemplar y practicar, es gratuidad y justicia, es mística y profecía.

El lenguaje de la gratuidad da horizonte al de la justicia, lo coloca en el marco del amor gratuito de Dios, de Dios como amor. Dios no es amor porque ama, sino que ama porque es amor. No es justo porque hace justicia, sino que hace justicia porque es justo. Este poner el lenguaje de la gratuidad, de la justicia, en este marco del amor, y yo diría de la fineza también en el trato con el otro, de la amistad, le puede quitar una cierta dureza al lenguaje de la justicia, que se preocupa más de la justicia que de la persona que vive la injusticia. El lenguaje de la gratuidad le da sentido, le da horizonte. Y a su vez, el lenguaje de la justicia le da concreción histórica al de la gratuidad o al contemplativo, porque de otra manera el lenguaje de la gratuidad corre el gran peligro de ser etéreo.

Volvamos a monseñor Romero. ¿Podemos decir que esta expresión de cercanía personal le quitó concreción histórica y le quitó fuerza para defender los derechos de esas personas maltratadas? De ninguna manera. Le dio más bien fuerza para hacerlo. ¿Podríamos decir que su lucha por la justicia le hizo olvidar la acción de gracias? Jamás. Me parece que, una vez más, como en el caso de las dos vertientes o de las dos memorias, Romero es alguien que justamente al tener en cuenta esas cosas, que están en la Biblia, en el mensaje de Cristo, al juntarlas hizo que adquirieran una fuerza, una dimensión y un alcance muy grande, mucho más que si se quedara con una de las partes y descuidara la otra.

\section{Pobreza espiritual y pobreza real}

Estas dos cosas, estas dos indicaciones de memoria, caminar por estos dos carriles, se entrelazan. Me refiero a la "pobreza espiritual", que tiene como texto mayor, no el único, "bienaventurados los pobres de espíritu". La pobreza espiritual muchas veces la tomamos como desprendimiento de los bienes de este mundo, pero no es esa la primera acepción. Esto es consecuencia de otra cosa mucho más honda, y es poner nuestras vidas en manos de Dios. Eso es la pobreza espiritual. Naturalmente, una consecuencia ineludible es estar desprendido de los bienes de este mundo. No se trata de no considerarlos. El mensaje de ese texto, como ocurre con otros de los Evangelios, no comunica a veces lo esencial de la confianza en la Providencia. Es el único texto poético de Mateo, quien no tenía vena poética, aunque sí otras. En realidad el gran tema es la libertad: "no se afanen, no se afanen", dice seis veces. "No se preocupen, no se afanen".

¿Cómo podemos ser libres en la vida cotidiana? Estableciendo prioridades, sabiendo qué es primero, qué es segundo y qué es tercero. Eso es lo que nos 
hace libres. Cuando Jesús dice: "vean los lirios del campo, qué bien se visten", lo que trata de decir es que la vida es lo primero, es más que el alimento y el vestido. Es una cuestión de prioridad. A mí me parece que la pobreza espiritual es fundamentalmente poner nuestras vidas en manos de Dios, casi sinónimo de otra expresión evangélica que conocemos bien: la de la "infancia espiritual". La "infancia espiritual", como la "pobreza espiritual", son metáforas. Se toma una noción de un campo semántico, se pasa a otro y se conserva un carácter del anterior. ¿Cuál es el carácter que se conserva en la "pobreza espiritual"? El pobre no es capaz de bastarse a sí mismo, y eso pasa a la "pobreza espiritual". Ante el Señor somos pobres espirituales, como lo dice muy bien Pablo en Efesios, aunque también dice: "no sean niños, sean maduros". La "infancia espiritual" es también una metáfora. Una persona de 80 años - disculpen el número que acabo de poner, pero lo tengo tan cerca en mi vida - puede ser un infante espiritual, un niño espiritual.

El "pobre espiritual" es lo mismo. Es sinónimo de "infancia espiritual". Y entonces es algo muy profundo. Es lo que Juan pone en boca de Jesús, quien "se alimenta de la voluntad del Padre". La "pobreza espiritual" es alimentarme de la voluntad del Padre. De nuevo, poner nuestras vidas en manos de Dios. Y ahí sí podemos entender el desprendimiento de los bienes de este mundo, lo que es una consecuencia. ¿Cómo vivir la pobreza o infancia espiritual si nos apegamos a los bienes de este mundo? No es que no los necesitemos, pero la misma pobreza espiritual nos lleva a una vida pobre, a establecer prioridades.

Volveré sobre esto, pero ahora quiero pasar a la otra acepción bíblica de nuestro término, la que podemos analizar socialmente. Es la "pobreza real", que a veces calificamos de "pobreza material", aunque prefiero mantenerme en lenguaje más bíblico. "Material" no se dice nunca, es una noción que proviene de otro horizonte ideológico, aunque no importa. En definitiva, son sinónimos.

¿Qué cosa es "la pobreza real”? La pobreza real es la pobreza tal como está, la que viven los pobres, es insuficiencia, y en la región teológica en este continente lo hemos trabajado naturalmente por razones fundamentales. La "pobreza real" es, en última instancia, "muerte injusta" y "muerte temprana". Eso es "la pobreza real" y es una cosa compleja. Naturalmente, la palabra "pobreza" evoca siempre una cuestión económica, y es una dimensión de la "pobreza" en la Biblia. Pero en la Biblia la "pobreza" no se reduce al lado económico por importante que sea.

Por eso, en reuniones teológicas hablamos del pobre como "insignificante". No es que uno quiera reemplazar la palabra "pobre". Esa palabra está en la Biblia, y la teología tiene que respetar ese lenguaje, pero la explicamos diciendo que se trata de "insignificante". Una persona puede ser insignificante por muchas razones. Porque no tiene dinero, claro está, pero insignificante también por el color de la piel, insignificante porque es mujer, insignificante porque pertenece a una cultura que la cultura dominante considera inferior. Todos esos son aspectos 
de la pobreza. Yo no he eliminado el aspecto económico, y, además, como todos saben, los aspectos que acabo de decir se cruzan entre ellos. Entonces, pobreza es "insignificancia".

Además, aunque durante siglos no se habló así, la pobreza tiene causas humanas, es resultado de nuestras manos. Y si es resultado de nuestras manos, así como la hicimos, la podemos deshacer. La pobreza no es una fatalidad, es una injusticia, no un destino. En muchos lugares en nuestro continente existe esta noción: "qué lástima, nacieron pobres". Y entonces, ¿qué queda? "Otros nacen ricos...". Eso lo encontramos también en el magisterio. Hasta Pío X, en el siglo $\mathrm{XX}$, todavía se hablaba así.

El papa que más ha hablado de las causas de la pobreza - no fue el primero, pues el primero fue Juan XXIII y siguió Pablo VI- ha sido Juan Pablo II. Habló de las causas de la pobreza con mucha fuerza, de muchas maneras. Eso supone un análisis de la realidad. Tenemos que conocerla para que no ocurra lo que decía un amigo mío: "qué bien estaríamos si no fuera por la realidad". Y hay gente que vive como si no existiera la realidad, y la realidad no les importa mucho porque les incomoda.

Cuando hay un pastor como Romero que recuerda "la realidad", porque eso fue lo que hizo, la gente se complica, y dicen que está creando un conflicto que, según ellos, no existía: increíble para un razonamiento incluso elemental, y sin embargo eso se dio en su caso y en otros casos más. La pobreza real es eso. Por eso, el compromiso, la solidaridad con los pobres, es lo que Medellín precisó bien. Permítanme que lo recuerde en pocas líneas: "La pobreza, como compromiso, se asume voluntariamente y por amor a la condición de los necesitados de este mundo... y para testimoniar el mal que ella representa y la libertad espiritual frente a los bienes". El compromiso con los pobres significa, entonces, rechazo de la pobreza como un mal y amor al pobre, al que sufre. Nos comprometemos con los pobres no por amor a la pobreza, que mata tempranamente a la gente, que posterga, que los hace sentirse inferiores, que les impide entenderse como personas. Alguno de ustedes podrá decir que a eso se llama "miseria", pero yo digo "pobreza" para abreviar y porque el término es más evangélico. Se trata de rechazo a la pobreza inhumana, "antievangélica" dice Puebla, y de solidaridad para con el pobre.

No hay que extrañarse. Cuando Pablo dice que Jesús toma sobre sí los pecados de este mundo, no se refiere a que lo hace por amor al pecado, sino por amor a los pecadores. Es importante. Romero decía: "hacerse pobres e interesarse por la pobreza de nuestro pueblo como si fuera nuestra propia familia". Es muy preciso y se entiende. La gente no quiere que su hijo sea pobre, que su esposa, que un sobrino, que un tío, sean pobres. De eso se trata, de hacerse pobre e interesarse por la pobreza de nuestro pueblo como si fuera nuestra propia familia. Así es en realidad, en un sentido naturalmente amplio. Pero, una vez más, estamos ante 
cosas que tampoco podemos separar: la pobreza espiritual, sinónimo de infancia espiritual, y el compromiso con la pobreza real en el sentido que acabo de afirmar. Se reúnen en la expresión "opción preferencial por el pobre".

La palabra "preferencial" proviene de la frase de Juan XXIII "la Iglesia de todos y particularmente de los pobres". "Preferencial" no quiere hacer olvidar que Dios ama a toda persona, nos guste o no. Ama a toda persona y espera la conversión de toda persona cualquiera que ella sea. Pero tan fuerte como eso es la afirmación de que "los primeros son los últimos". Primero son los marginados, los expoliados, los maltratados, los pobres. Eso es lo que quiere decir la palabra "preferencial", que no la entendemos si quitamos el marco de la universalidad, que es un dato del mensaje cristiano. La universalidad del amor de Dios es un dato central, el de la preferencia también. Los dos, y no hay contradicción entre ambas cosas.

Algunos hacen realmente gimnástica mental para decir "preferencial, pero no exclusiva". Si es preferencial, ¿cómo va a ser exclusiva? Es un pleonasmo. Preferencia y universalidad están en tensión, no en contradicción. Como oración y acción no se contradicen, pero están en tensión. La opción preferencial es cuando decimos "los pobres son los primeros". Eso es preferencial. Pude haber dicho también "prioritario", "privilegiado". Las palabras son tan ricas, hay tantos sinónimos, que podemos decir lo que queramos. Lo que importa es no perder de vista la universalidad del amor de Dios ni que los más débiles, los postergados, los insignificantes, son los primeros.

Vivir estas dos pobrezas supone una conversión. Nuestro congreso tiene como subtítulo "conversión y esperanza". Ciertamente, supone una conversión. El texto de Puebla sobre "opción preferencial por el pobre" menciona la palabra "conversión" seis veces. Cada cristiano, y también la Iglesia entera, deben convertirse. Antes de pasar a mi conclusión, leo una frase de monseñor Romero: "Es inconcebible que se diga alguien cristiano y no tome, como Cristo, una opción preferencial por los pobres". La frase es nueva, el contenido es muy antiguo. Uno abre la Biblia donde sea y hay una preferencia por el más pobre. Un teólogo como Karl Barth, que tiene fama de hablar de Dios y de la trascendencia, tiene un texto en donde dice: "Dios siempre toma partido por el pobre y contra el rico". No sé cómo le fue en Suiza. Simplemente, leyó la Biblia. Nada más. Uno la abre y se da cuenta.

\section{Conclusión}

Tengo tres puntos en la conclusión. El primero es recordar que una Iglesia de los pobres es una Iglesia que hace suya la práctica de Jesús, que comunica esos lenguajes de gratuidad y de justicia, proféticos y místicos, y que vive la pobreza espiritual y el compromiso con el pobre. No puedo ahora tener presente la práctica de Jesús, pero quiero insistir en que ese mensaje nunca ha sido para 
uno mismo, uno lo tiene que comunicar como Andrés, el hermano de Pedro. Encuentra a Jesús y sale a buscar a su hermano, siempre hay algo de eso, y luego tiene que vivir estas dos condiciones fundamentales para que sea auténtico el testimonio que damos: la memoria de la vida de Jesús y el servicio al pobre.

Segunda cuestión. Romero fue un predicador de la esperanza, constantemente, y también decía: "A mí me toca recoger cadáveres". Y, sin embargo, fue un testigo de esperanza. Leo un texto suyo: "A ustedes les consta cuál es el lenguaje de mi predicación, un lenguaje que quiere sembrar esperanza, que denuncia sí las injusticias de la tierra, los abusos del poder, pero no con odio, sino con amor, llamando a la conversión". Tienen en esta frase tanto la esperanza como la conversión.

Ahora bien, la esperanza es un don, es una gracia, pero no hay gracia que no implique tarea. La gracia no es para que me la guarde yo, implica siempre una tarea, una comunicación. Por ello, ¿cómo recibimos el don de la esperanza? Forjando motivos de esperanza. Es así como lo recibimos. Cuando me preguntan por la esperanza, les digo: "Voy a tratar de contestar, pero antes me vas a contestar a una pregunta: '¿Qué motivos de esperanza estás tú forjando?'. '¿Yo?'. 'Si tanto te interesa, comienza tú. Es lo menos que puede hacer'”. Solamente si yo creo motivos de esperanza, acojo realmente la esperanza. La esperanza no es una palmada en el hombro, no es crear ilusiones. Tampoco es aguardar, esperar. Eso es perder el tiempo. La esperanza es lo que Romero ha procurado decir al pueblo de este país, al pueblo de América Latina y más allá: que hay una esperanza a mantener y que debemos crear.

Hablé de revisión de vida al comienzo. No se puede uno confrontar con el Evangelio, sobre todo vivido como lo vivió Romero, sin preguntarnos dónde estamos en nuestra vida de todos los días. La teología es una hermenéutica de la esperanza; si alguna razón hay para reflexionar sobre la fe, es para tratar de leer la historia y entender dónde está la esperanza. Los motivos de esperanza que hay pueden ser ligeros, pero recordemos ese bello texto de Isaías: "no apagará la mecha humeante, no quebrará la caña cascada". Eso es, pues, y eso fue Romero. Romero no fue tanto alguien que vivió una situación excepcional. Lo excepcional en Romero es la manera cómo confrontó la situación que se vivía. Lo que quiero decir es lo siguiente. A veces temo que encerremos a Romero como en una burbuja. "Claro, él respondió a una situación 'muy' diferente a la mía, totalmente distinta". Pues no se ha entendido nada, porque el maltrato al pobre sigue estando presente en este continente. Cuando la gente dice "que se le aplique todo el peso de la ley", pienso qué ganamos con aplicar todo el peso de la ley, si en este continente, por lo menos en mi país para ser más modesto, hasta la ley de gravedad de Newton tiene problemas para cumplirse. En la economía, en mi país, cuando "chorrea", chorrea para arriba. Las leyes no funcionan, pero buscar 
eso es la teología. La teología es tratar de interpretar. No es una cosa enteramente optimista. No hablo de optimismo, hablo de esperanza, que puede ser difícil.

Un último punto. Creo que, como a Cristo, a monseñor Romero no hay que buscarlo entre los muertos, hay que buscarlo entre los vivos. Ayer se nos presentó un hermoso cuaderno sobre monseñor de alguien que hizo un esfuerzo muy grande para hacerlo y presentarlo, y tiene toda nuestra admiración. Vean la última página. Es una foto de Romero. Y abajo, estas palabras: "Está vivo". Eso es. Está vivo. 